\title{
Generation and gender factors of the structure of value orientations
}

\author{
Nadezhda Sivrikova ${ }^{1, *}$, Tatyana Ptashko $^{1}$, Elena Chernikova $^{1}$, Elena Moiseeva ${ }^{1}$ and \\ Svetlana Roslyakova ${ }^{1}$ \\ ${ }^{1}$ South Ural State Humanitarian Pedagogical University, Chelyabinsk Lenin prospect, 69, Russia
}

\begin{abstract}
A great interest in the study of the value orientations of a person is explained by their decisive role in explaining human behavior. Previous studies have shown that demographic factors influence people's value system. Over the past 20 years, several mass surveys have been conducted with wide geography. Their results showed that in the world there are processes of transformation in the structure of cultural values of different communities of people. The aim of this study was to examine the effects of generation and gender factors on value orientations. The study was based on Schwartz's theoretical model of cultural values. The survey was attended by 384 residents of Chelyabinsk and the Chelyabinsk region (Russia). To collect empirical data, Schwartz's questionnaire in Russian was used. The study found that representatives of the Soviet generation are more oriented towards conservative values, and representatives of the post-Soviet generation more adhere to values reflecting their openness to experience. In this study, men differed from women in a greater commitment to the values of autonomy and power. Considering the values of generations in the context of the gender of respondents, it is found that hedonistic values and the desire for stimulation and power are represented by a U-shaped curve in men and an inverted U-shaped curve in women. This allows us to conclude that in Russia, conditions of economic stabilization lead to increased openness to experience and dominance among men. For women, these conditions make the desire for dominance and high social status less significant.
\end{abstract}

\section{Introduction}

Interest in the problem of personal values is determined by their decisive role in regulating human behavior. Values are concepts or standards that guide a person to a particular action or state [1]. Therefore, a large number of scientific papers are devoted to the study of values and value orientations.

Researchers have shown that personality value orientations are influenced by demographic factors such as age and gender [1-5]. At the same time, the focus of the researchers is adolescence, as sensitive for the formation of the value-sense sphere of personality [2-5]. Researchers compare the values of adolescents with the values of adults [2] or the values of adolescents of different ages [1]. Often, these studies consider the gender factor. Some researchers were able to establish the effect of gender on the structure of value

\footnotetext{
* Corresponding author: bobronv@cspu.ru
} 
orientations [5, 6], while others did not [2]. Little attention is paid to the joint influence of age and gender factors on human values. At the same time, researchers believe that cultural values and their interaction with gender are an important factor in human behavior [7].

In the context of value analysis, mass surveys of people from different countries deserve attention [4, 7-10]. Ronald Inglehart and Wayne E. Baker used data from 3 waves of value surveys around the world found evidence of significant changes in some and the preservation of other cultural traditions [9]. Florencia M. Sorteix and Shalom H. Schwartz explain the dynamics of basic cultural values through contrasting orientations on growth and security or through contrasting person focus or social focus [11]. Other researchers show how the behavior of people in countries with different value systems differs. For example, traditional gender roles are manifested in societies with a focus on hierarchy and affiliation, while progressive views are more pronounced in egalitarian societies [8]. It was found that society's commitment to autonomy and hierarchy is associated with a higher level of conflict between family and work [4].

The results of a mass online survey showed that the subjective well-being of a person depends more on the cultural values of society than on the level of wages in it [12]. The results of such studies indicate the relevance of the study of value orientations of large social communities.

In this study, values are considered as a semantic element of generational mentality. At the same time, generations act not just as age groups, but as large communities of people who are connected by the general cultural and historical context of formation and development.

Many researchers note that the structure of values of such large social groups as generations differs from each other. This leads to a complication of social relations. In particular, differences in value orientations explain the intergenerational conflict [13, 14], workplace tensions [15], as well as other problems of intergenerational communication [16, 17]. At the same time, at the moment, the cultural values of generations are not sufficiently studied.

Therefore, the purpose of this study was to study the influence of generation and gender factors on people's value orientations.

\section{Research Methods}

Schwartz's model of cultural value orientations formed the methodological basis of this study. It is based on Schwartz's theory of human values and is associated with other influential models of cultural values, such as the Hofstede model and Inglehart's theory of modernization [7]. According to this model, 10 basic cultural value orientations can be combined into 4 groups: Self-Transcendence, Conservation, Self-Enhancement, Openness to Change. In turn, these 4 groups are divided into 2 parts: personal focus, social focus [18].

The study was a survey in which 384 residents of Chelyabinsk and the Chelyabinsk region took part. The gender and age composition of the sample is shown in Table 1. During the study, groups were formed for comparative analysis. At the same time, we proceeded from the division of modern Russian society into 3 generations: Soviet, transitional, and postSoviet. This generational classification is based on the idea of the commonality of a single cultural and historical context of the formation of representatives of one generation. At the same time, the collapse of the USSR is considered as the most important historical factor determining the formation of the personality of Russian citizens. Representatives of the Soviet generation are people who were born and raised in the USSR. People born and raised in the era of perestroika and the collapse of the USSR belong to representatives of the transitional generation. Those whose formation was during the stabilization of the Russian economy belong to the post-Soviet generation. 
Table 1. Sampling characteristics.

\begin{tabular}{|c|c|c|c|c|}
\hline Gender & $\begin{array}{c}\text { Post-Soviet } \\
\text { generation } \\
\text { 16-32 years old }\end{array}$ & $\begin{array}{c}\text { Transition } \\
\text { Generation } \\
\text { 33-45 years old }\end{array}$ & $\begin{array}{c}\text { Soviet generation } \\
\text { 46-65 years old }\end{array}$ & Total \\
\hline male & 64 & 64 & 64 & 192 \\
\hline female & 64 & 64 & 64 & 192 \\
\hline Total & 128 & 128 & 128 & 384 \\
\hline
\end{tabular}

Schwartz's questionnaire in Russian was used to collect empirical data.

Kolmogorov-Smirnov test indicates that the level of significance of the values studied do not follow a normal distribution (Table 2). Therefore, non-parametric methods of mathematical statistics were used to prove hypotheses. In particular, two-factor dispersion analysis was used. During the study, the gender and age (generation affiliation) of respondents was considered as value factors.

Table 2. Descriptive statistics of the variables studied.

\begin{tabular}{|l|c|c|c|c|c|}
\hline \multicolumn{1}{|c|}{ Values } & Number & Mean & $\begin{array}{c}\text { Standard } \\
\text { deviation }\end{array}$ & $\begin{array}{c}\text { Kolmogorov- } \\
\text { Smirnov test } \\
\text { statistic }\end{array}$ & $\begin{array}{c}\text { Statistical } \\
\text { significance }\end{array}$ \\
\hline Conformity & 384 & 4.5 & 1.3 & 0.12 & 0.00001 \\
\hline Tradition & 384 & 3.6 & 1.5 & 0.07 & 0.00001 \\
\hline Benevolence & 384 & 4.9 & 1.1 & 0.08 & 0.00001 \\
\hline Universalism & 384 & 4.6 & 1.2 & 0.084 & 0.00001 \\
\hline Self-Direction & 384 & 4.7 & 1.1 & 0.08 & 0.00001 \\
\hline Stimulation & 384 & 4.1 & 1.5 & 0.07 & 0.00001 \\
\hline Hedonism & 384 & 4.2 & 1.5 & 0.11 & 0.00001 \\
\hline Achievement & 384 & 3.5 & 1.0 & 0.10 & 0.00001 \\
\hline Power & 384 & 3.4 & 1.4 & 0.06 & 0.003 \\
\hline Security & 384 & 5.1 & 1.1 & 0.11 & 0.00001 \\
\hline
\end{tabular}

Mathematical calculations were carried out using IBM SPSS Statistics 23.

\section{Results}

Analysis of average trends reflecting the value system in the study sample showed that life principles such as kindness and safety were the most priority for study participants. The least significant were power, achievements, and traditions (table 2). This structure of values does not depend on the gender of respondents. Although among the male participants in the study, the principle of autonomy was also among the priorities in addition to the above.

During the study, it was found that representatives of different sexes differ from each other in their attitude to values independence and power (Table 3). They turned out to be more significant for men than for women.

Table 3. Gender factor in value orientations.

\begin{tabular}{|l|c|c|c|c|}
\hline Dependent variable & male & female & F & p \\
\hline Conformity & 4.4 & 4.6 & 2.31 & 0.13 \\
\hline Tradition & 3.6 & 3.5 & 0.75 & 0.39 \\
\hline
\end{tabular}




\begin{tabular}{|l|c|c|c|c|}
\hline Benevolence & 4.8 & 4.9 & 0.66 & 0.42 \\
\hline Universalism & 4.6 & 4.6 & 0.01 & 0.92 \\
\hline Self-Direction & 4.8 & 4.5 & 5.42 & 0.02 \\
\hline Stimulation & 4.1 & 4 & 0.37 & 0.54 \\
\hline Hedonism & 4.3 & 4 & 3.42 & 0.07 \\
\hline Achievement & 3.6 & 3.5 & 1.67 & 0.2 \\
\hline Power & 4.4 & 4.6 & 2.31 & 0.13 \\
\hline Security & 3.6 & 3.5 & 0.75 & 0.39 \\
\hline
\end{tabular}

To a greater extent, the structure of respondents' values depends on the age factor (Table 4). Moreover, for representatives of older generations (transitional and post-Soviet), it is similar. It is dominated by the values of security and kindness. Among the low values are power and achievements. The values of independence and hedonism are the priority in the structure of values of the post-Soviet generation. And among the insignificant values are those that are part of the "tradition" group.

Differences were established in the level of significance of the values studied among representatives of different generations. The values belonging to the conformality and tradition groups are most significant for representatives of the transitional generation, and the least significant for representatives of the post-Soviet generation. The importance of safety increases with the age of respondents. And the importance of achievement, hedonism, and stimulation decreases with age. Independence is more appreciated by representatives of the post-Soviet generation, and least of all - representatives of the Soviet generation.

Gender and generational factors have a joint effect on the structure of people's values (Table 5).

Table 4. Co-influence of gender and generation factors on individual value orientations.

\begin{tabular}{|c|c|c|c|c|c|c|}
\hline $\begin{array}{l}\text { Dependent } \\
\text { variable }\end{array}$ & gender & $\begin{array}{c}\text { Post- } \\
\text { Soviet } \\
\text { generation }\end{array}$ & $\begin{array}{l}\text { Transition } \\
\text { generation }\end{array}$ & $\begin{array}{c}\text { Soviet } \\
\text { generation }\end{array}$ & $\mathbf{F}$ & $\mathbf{p}$ \\
\hline \multirow{2}{*}{ Conformity } & male & 4.04 & 4.38 & 4.66 & \multirow{2}{*}{1.94} & \multirow{2}{*}{0.144} \\
\hline & female & 4.20 & 4.92 & 4.56 & & \\
\hline \multirow{2}{*}{ Tradition } & male & 3.06 & 3.87 & 3.92 & \multirow{2}{*}{0.41} & \multirow{2}{*}{0.663} \\
\hline & female & 2.86 & 3.93 & 3.70 & & \\
\hline \multirow{2}{*}{ Benevolence } & male & 4.91 & 4.64 & 4.91 & \multirow{2}{*}{1.73} & \multirow{2}{*}{0.178} \\
\hline & female & 4.85 & 5.01 & 4.86 & & \\
\hline \multirow{2}{*}{ Universalism } & male & 4.34 & 4.58 & 4.75 & \multirow{2}{*}{0.85} & \multirow{2}{*}{0.429} \\
\hline & female & 4.51 & 4.65 & 4.54 & & \\
\hline \multirow{2}{*}{ Self-Direction } & male & 5.14 & 4.53 & 4.67 & \multirow{2}{*}{1.11} & \multirow{2}{*}{0.331} \\
\hline & female & 4.81 & 4.50 & 4.25 & & \\
\hline \multirow{2}{*}{ Stimulation } & male & 4.42 & 3.74 & 4.15 & \multirow{2}{*}{4.94} & \multirow{2}{*}{0.008} \\
\hline & female & 4.34 & 4.23 & 3.46 & & \\
\hline \multirow{2}{*}{ Hedonism } & male & 5.20 & 3.64 & 4.02 & \multirow{2}{*}{7.46} & \multirow{2}{*}{0.001} \\
\hline & female & 4.45 & 4.14 & 3.49 & & \\
\hline \multirow{2}{*}{ Achievement } & male & 3.82 & 3.51 & 3.44 & \multirow{2}{*}{1.33} & \multirow{2}{*}{0.265} \\
\hline & female & 3.60 & 3.61 & 3.17 & & \\
\hline
\end{tabular}




\begin{tabular}{|l|c|c|c|c|c|c|}
\hline \multirow{2}{*}{ Power } & male & 3.99 & 3.41 & 3.42 & \multirow{2}{*}{4.00} & \multirow{2}{*}{0.019} \\
\cline { 2 - 5 } & female & 3.05 & 3.41 & 3.14 & & \\
\hline \multirow{2}{*}{ Security } & male & 4.78 & 5.13 & 5.28 & \multirow{2}{*}{0.79} & \multirow{2}{*}{0.454} \\
\cline { 2 - 5 } & female & 4.64 & 5.32 & 5.28 & & \\
\hline
\end{tabular}

Differences were established in the level of significance of the values of stimulation, hedonism, and power.

The significance of novelty and deep experiences in women reaches maximum values among representatives of the post-Soviet and transitional generations, and among male representatives among representatives of the post-Soviet and Soviet generations (Figure 1).

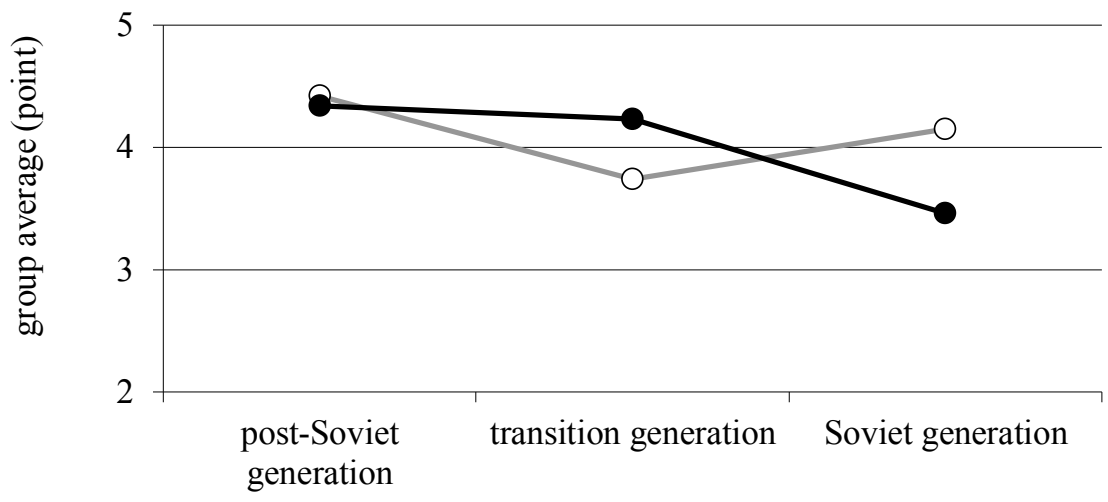

- male $\quad \longrightarrow$ female

Fig. 1. Gender and generation dependence of Stimulation values.

The importance of the search for pleasures and the desire for pleasure reaches the maximum value in men belonging to the post-Soviet generation, and the minimum - in women belonging to the Soviet generation (Figure 2).
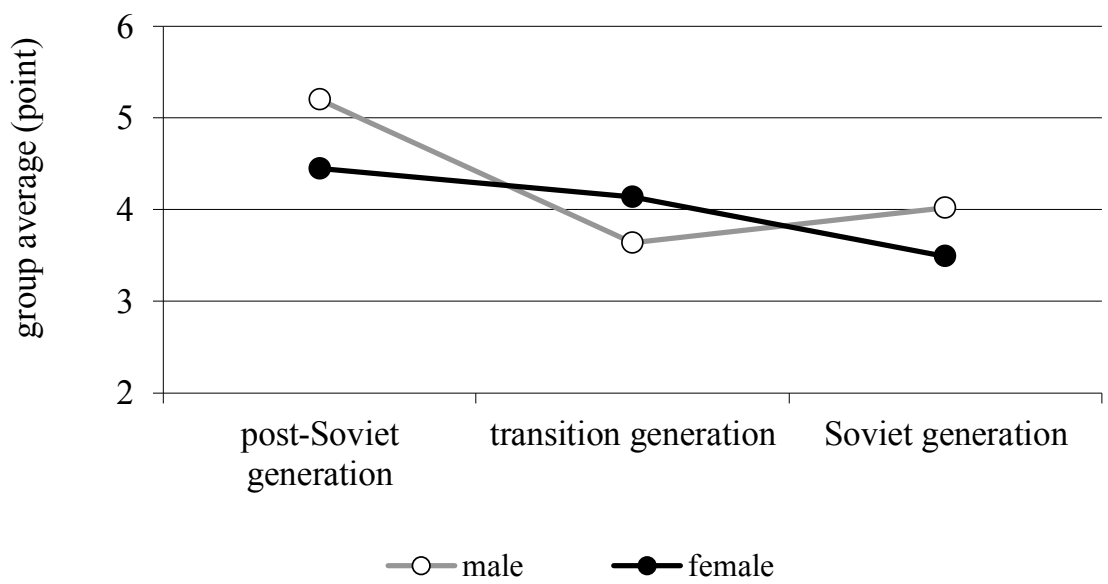

Fig. 2. Gender and generation dependence of Hedonism values. 
Achieving social status or prestige, control or dominance over people is most valuable for representatives of the post-Soviet generation of males and least valuable for representatives of the same generation of females (Figure 3).

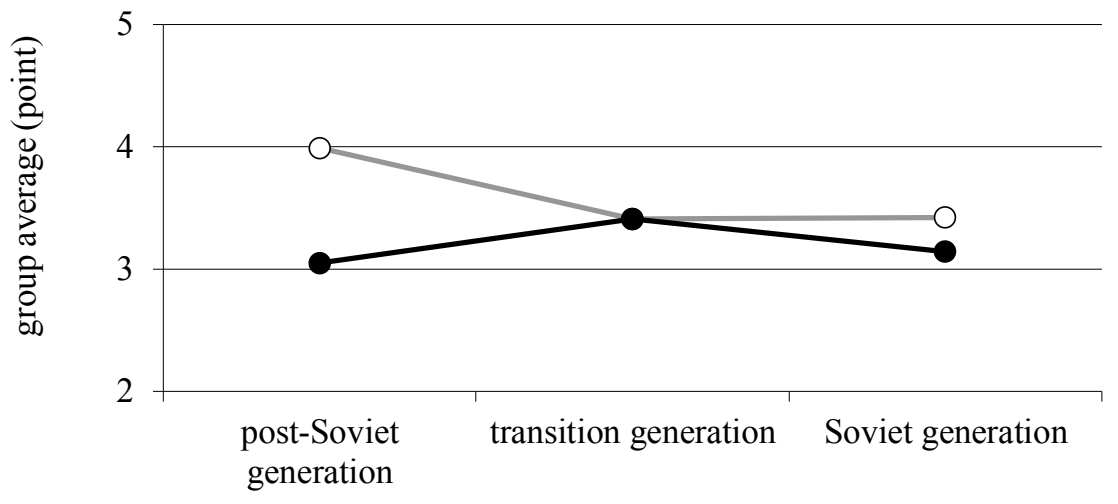

- - male $\quad \longrightarrow$ female

Fig. 3. Gender and generation dependence of Power values.

\section{Discussion}

In this paper, we extend scientific insights into the effects of age and sex factors on the values considered in the Schwartz concept. The differences found to demonstrate the commitment of members of different genders and generations to opposite values. In particular, it was found that representatives of the Soviet generation are more focused on conservative values than other generations, while representatives of the post-Soviet generation are more open to the experience. In part, the results of our study confirm global trends in differences in values between generations. In particular, as in other culturally collectivistic society, the study sample shows a tendency to increase the significance of status and individualistic functions among representatives of the new generation (post-Soviet) [10].

Interestingly, the differences found during the study in respondents of different sexes did not coincide with data from other studies. Female participants had higher estimates of conservative values than male participants in the Renata M. Heilman and Petko Kusev study [6]. Men had a higher orientation to hedonism and stimulation than women in the Irem MetinOrta and Kursad Demirutku study [19]. In our study, men differed Such discrepancies are an indirect confirmation of the fact that the influence of gender on people's values is indirect to culture.

The most important are the results of the study, indicating the nature of the joint influence of age and generation factors on human value orientations. Considering the values of generations in the context of the sex of respondents, it is found that hedonistic values and the desire for stimulation and power are represented by a U-shaped curve in men and an inverted U-shaped curve in women. Such patterns indicate that in our country, conditions of economic stabilization lead to increased openness of experience and dominance among men, and conditions of instability and deep political crisis lead to a weakening of these orientations. In the context of the stabilization of society, women's desire for dominance and the importance of social status are weakening. 


\section{Conclusion}

The results of the study showed that the existing differences in the values of generations of modern Russia lie in a greater orientation of older generations to conservative values, and younger generations to openness to experience. This allows us to say that the post-Soviet generation focuses more on the individual, and the Soviet generation focuses more on society. Thus, the results confirm that in Russian society there are the same trends in the transformation of the mentality of generations as throughout the world. The new generation is more focused on individualistic values than their parents and progenitors. Moreover, representatives of the Soviet and post-Soviet generations adhere to opposite value orientations, which can explain the growing conflict of generations in society.

An analysis of generational values taking into account the gender factor suggests that the latter makes a significant contribution to the significance for a person of social status, pleasure, and new impressions.

The practical significance of the study results is determined by their importance in assessing intergenerational relationships in the family and at work. They allow you to predict the behavior of different categories of citizens. The intergenerational differences found in the study will be useful in resolving intergenerational conflicts.

A significant limitation of this study is the cross-sectional methodology. It allows us to talk about the existence of differences between people, depending on gender and age, but not about the dynamics of the values of generations. Despite this, the results of the study revealed new facts about the values of generations functioning in Russia at the moment.

\section{Acknowledgements}

Work supported by the Russian Foundation for Humanities project № 18-013-00910.

\section{References}

1. G. Livazović, M. Matić, Curr. Psychol. (2020) https://doi.org/10.1007/s12144-0189858-y

2. E.H. Yaban, M. Say1, J. Gen. Psychol. 147, 335-360 (2020) https://doi.org/10.1080/00221309.2019.1665490

3. A. Germani, E. Delvecchio, J. Li, C. Bin, J. Mazzeschi, Child Fam. Stud. 29, 904-911 (2020) https://doi.org/10.1007/s10826-019-01571-w.

4. A.D. Masuda, F.M. Sortheix, B. Beham, L.J. Naidoo, J. Vocat. Behav. 112, 294-310 (2019) https://doi.org/10.1016/j.jvb.2019.04.001

5. M.S. Yanitskij, A.V. Seryj, O.A., Braun, et al, Sib. Psikhologicheskiy Zhurnal, 46-67 (2019) https://doi.org/10.17223/17267080/72/3

6. R.M. Heilman, P. Kusev, Behav. Sci. (Basel) 10, 1-9 (2020) https://doi.org/10.3390/bs10040077

7. R.A. Inman, S.M.G. da Silva, R.R. Bayoumi, P.H.P. Hanel, Front. Psychol. 8, 1963 (2017) https://doi.org/10.3389/fpsyg.2017.01963

8. V. Lomazzi, D. Seddig, Cross-Cultural Res. 54, 398-431 (2020) https://doi.org/10.1177/1069397120915454

9. R. Inglehart, W.E. Baker, Am. Sociol. Rev. 65, 19-51 (2000) https://doi.org/10.2307/2657288

10. N. Sivrikova, T. Ptashko, E. Chernikova, A. Perebeynos, Values dependence on 
generation identification https://doi.org/10.1051/shsconf/20196900108

11. F.M. Sortheix, S.H. Schwartz, Eur. J. Pers. 31, 187-201 (2017) https://doi.org/10.1002/per.2096

12. P. Steel, V. Taras, K. Uggerslev, F. Bosco, Soc. Psychol. Rev. 22, 128-169 (2018) https://doi.org/10.1177/1088868317721372

13. M.J. Urick, E.C. Hollensbe, S.S. Masterson, S.T. Lyons, Work. Aging Retire 3, 166-185 (2017) https://doi.org/10.1093/workar/waw009.

14. V.I. Pishchik, N.V. Koroleva, Soc. Psychol. Soc. 9, 78-89 (2018) https://doi.org/10.17759/sps.2018090106

15. A. de Waal, L. Peters, M. Broekhuizen, J. Strateg. Manag. 10, 86-101 (2017) https://doi.org/10.1108/JSMA-10-2015-0083

16. D.P. Costanza, L.M. Finkelstein, Ind. Organ. Psychol. 8, 308-323 (2015) https://doi.org/10.1017/iop.2015.15

17. V. Pishchik, Eur. Proc. Soc. Behav. Sci. XLIII, 461-468 (2018) https://doi.org/10.15405/epsbs.2018.07.60

18. S.H. Schwartz, Handbook of Value (Oxford University Press, 2015) https://doi.org/10.1093/acprof:oso/9780198716600.003.0004

19. I.,Metin-Orta, K. Demirutku, Curr. Psychol (2020) https://doi.org/10.1007/s12144-02000932-9 